\title{
A PIRATARIA DO NOME DE DOMÍNIO NA INTERNET
}

\author{
Ligia Maura Costa \\ Doutora em Direito pela Universidade de Paris-X, Professora do Departamento \\ de Fundamentos Sociais e Jurídicos da Administração da FGV/EAESP e Advogada e \\ Sócia de Lilla, Huck, Malheiros, Otranto, Ribeiro, Camargo e Messina Advogados. \\ E-mail:Imcosta@fgvsp.br
}

\begin{abstract}
Este artigo é parte de um projeto mais amplo: a influência da Internet na legislação brasileira. 0 rápido desenvolvimento da Internet, que abrange a troca de mercadorias e serviços, pode ser comparado à Revolução Industrial. A ausência total de fronteiras gera admiração e receio. A Internet é "independente". Entretanto, ela não pode susbsitir sem a influência de um sistema jurídico. Leis internas de vários países podem ser aplicadas, pois a Internet não tem uma legislação específica. Tais

leis, porém, não podem ser aplicadas imediatamente. É fundamental uma certa adaptação aos novos padrões legais utilizados na Internet. Neste estudo, atenção especial é dada ao registro de marcas e de nome de domínio.
\end{abstract}

RESUMO

\section{ABSTRACT}

This article is part of a larger project: the study of the influence of the Internet on Brazilian law. The quick development of the Internet, including the exchange of goods and services, can be compared to the Industrial

Revolution. The total absence of frontiers in the Internet is both admirable and fearful. The Internet is "independent"; however, it cannot subsist without the influence of a legal system. The national laws of any country are suited for application to the Internet because there is no single regulation. Nevertheless, such laws may not be applied directly because they would have to be adapted to the new legal patterns used in the Internet. This article pays special attention to trademarks and domain names piracy in the Internet.

Internet, nome de domínio, marca, propriedade intelectual, Direito Comercial. 


\section{INTRODUÇÃO}

A Internet ${ }^{1}$, um dos fenômenos mais importantes do fim do século passado, foi concebida nos idos de 1960. Suas origens militares e universitárias reúnem, num amálgama singular, aspectos econômicos e tecnológicos dos mais relevantes. Para alguns, trata-se de uma revolução técnica. Para outros, é uma revolução semelhante ao surgimento do alfabeto. Há quem considere sua aparição como comparável à invenção da imprensa. Seja como for, tanto uns quanto outros são unânimes em afirmar que o fenômeno da Internet suscita, ao mesmo tempo, receio e admiração (Bensoussan, 1996). O receio decorre do fato de escapar, à primeira vista, de qualquer controle regulador estatal. A admiração resulta da inexistência de fronteiras físicas.

\section{A INTERNET NÃO TEM UM} “COMANDO” JURÍDICO UNIFORMIZADO E HARMONIZADO. ELA É “INDEPENDENTE”. ASSIM, SOB O PRISMA DA LIBERDADE, A INTERNET VEM DERRUBANDO CONCEITOS JURÍDICOS

\author{
TRADICIONAIS.
}

A Internet não tem um "comando" jurídico uniformizado e harmonizado. Ela é "independente". Assim, sob o prisma da liberdade, a Internet vem derrubando conceitos jurídicos tradicionais. Entretanto, ela não pode subsistir sem a influência de um sistema legal. É quase desnecessário dizer que o rápido desenvolvimento da Internet não está permitindo que o Direito fique estático diante dessa transformação. De fato, "o Direito apoiava-se na concepção de que o mundo era feito de átomos e, por isso, as regras disciplinando as condutas humanas assumiam como referencial da disciplina certos conceitos ou figuras cujo substrato é formado por átomos" (Greco, 2000). Essa, porém, não é mais a realidade atual, pois o real tornou-se virtual. De qualquer maneira, as leis nacio- nais de um determinado país estão tendo aplicação na Internet, dada a inexistência de uma regulamentação específica. Essa aplicação, contudo, não se faz de forma imediata e, em alguns casos, nem mesmo de modo eficaz e eficiente. É certo que adaptações nos conceitos jurídicos tradicionais serão necessárias para atender aos novos modelos jurídicos utilizados na Internet. De fato, a história jurídica da Internet é ainda recente, pois a maior parte pertence, na realidade, ao futuro.

\section{INTERNET}

"A Internet nada mais é do que uma rede mundial de computadores que podem não só se comunicar e trocar mensagens, mas também trocar arquivos de dados e imagens entre si, tudo isso em tempo real" (Hey, 1995). O serviço de conexão à Internet é prestado pelos provedores de acesso. No Direito brasileiro, esse serviço é considerado como um serviço de valor adicionado. É nesse sentido que dispõe o art. 61 da Lei Geral de Telecomunicações (Lei no ${ }^{9}$ 9.472, de 16 de julho de 1997) ${ }^{2}$. Dessa forma, entende-se como serviço de valor adicionado todo serviço que se agrega a uma rede preexistente de serviços de telecomunicações, pela criação de utilidades específicas ou atividades produtivas novas, relacionadas com o acesso, o armazenamento, a movimentação e a recuperação de informação. Logo, os serviços de conexão à Internet oferecidos pelos provedores não são considerados serviços de telecomunicações ${ }^{3}$. Aliás, dois tipos de serviço são distintos e não devem ser confundidos. Isso porque o prestador de serviço de telecomunicações "é aquele que mantém em funcionamento os canais de transmissão de som ou sinais, e o seu cliente aquele que se utiliza de tal sistema para fazer chegar a outrem o som ou o sinal que ele tem a faculdade de emitir" (Brigagão, 1997). Daí decorre que a utilização dos serviços de valor adicionado não depende da obtenção de qualquer autorização da Agência Nacional de Telecomunicações (Anatel), pelo menos em princípio.

Embora a exploração dos serviços de conexão à Internet fornecidos pelos provedores independa de autorização da Anatel, é necessário, para isso, a utilização das redes de serviços de telecomunicações. Como essas redes dependem da autorização da Anatel para o seu funcionamento, coube a esta regulamentar o condicionamento do uso das redes de serviços de telecomunicações, bem como o relacionamento entre os provedores de serviços de conexão à Internet e as prestadoras de serviços de telecomunicações. 


\section{Redes públicas de telecomunicações}

As redes públicas de telecomunicações devem dar condições a todos os interessados em explorar serviços de conexão à Internet, desde que observadas certas condições técnicas e operacionais. Os provedores de Internet podem escolher, livremente, quaisquer serviços de telecomunicações oferecidos pelas exploradoras para a utilização de seus serviços ${ }^{4}$. Aos interessados nesse tipo de serviço, basta solicitar diretamente às prestadoras de serviços de telecomunicações o uso das redes de telecomunicações. Tal solicitação deverá ser feita por escrito e deverá conter as informações técnicas necessárias à obtenção do direito ao uso das redes de telecomunicações. As prestadoras de serviços de telecomunicações deverão responder a esses pedidos dentro de 30 dias. Note-se que será obedecida a ordem cronológica de recebimento de solicitações para o uso das redes de telecomunicações. Em princípio, a solicitação para o uso da rede não poderá ser negada, salvo por motivo de limitação da capacidade do sistema ou de condições determinadas no contrato de concessão ou no termo de autorização. As condições desse serviço serão diretamente negociadas entre os exploradores de serviços de conexão à Internet e as prestadoras de serviços de telecomunicações ${ }^{5}$.

Qualquer pessoa jurídica poderá explorar a atividade de provedor de conexão à Internet, desde que possua o equipamento técnico necessário e obtenha autorização para o uso das redes de telecomunicações. É também possível às prestadoras de serviços de telecomunicações fornecerem serviços de conexão à Internet. Para tanto, elas deverão constituir uma empresa especificamente para esse fim. A empresa prestadora de serviços de conexão à Internet deverá pagar uma taxa à prestadora de serviços de telecomunicações pelo uso da rede. Essa taxa é fixada pela própria prestadora de serviços de telecomunicações.

\section{REGISTRO DE NOME DE DOMÍNIO}

É quase desnecessário dizer que uma das conseqüências da inexistência de fronteiras na Internet é a ausência de um controle centralizado ou de um órgão regulador único. De qualquer modo, para viabilizar o fluxo de dados via Internet, era preciso determinar um endereço para a emissão e a recepção de dados e informações de cada computador a ela conectado. Esse endereço denomina-se Internet Protocol (IP). Ele é representado por um conjunto de quatro números, separados por pontos. Entretanto, a memorização de um conjunto de números seria muito difícil, para não dizer quase impossível.

Por essa razão, foi criado, além dos números, um sistema de nomes, o Domain Name System (DNS) Sistema de Nome de Domínio. Dentro da estrutura do

\section{É CERTO QUE ADAPTAÇÕES NOS CONCEITOS JURÍDICOS} TRADICIONAIS SERÃO NECESSÁRIAS PARA ATENDER AOS NOVOS MODELOS JURÍDICOS UTILIZADOS NA INTERNET. DE FATO, A HISTÓRIA JURÍDICA DA INTERNET É AINDA RECENTE, POIS A MAIOR PARTE PERTENCE, NA REALIDADE, AO FUTURO.

DNS, nasceram os chamados World Wide Web ("www", ou "web", ou "w3"), isto é, a "teia de alcance mundial" ", a marca nominativa que identifica o usuário, os Domínios de Primeiro Nível (DPNs) - top-level domain names (tld) -, que compreendem os DPNs genéricos (".gov", ".org", ".net", ".edu", entre outros") e os two letters country codes (“.br”, “.uk”, “.fr”, “.it”, “.pt”, etc.). Ainda nessa estrutura, ficou determinado que cada país constituiria um administrador responsável pela prestação de serviço público de interesse da comunidade "internética", incluindo, nessa prestação, a coordenação do registro de nome de domínio na Internet, sob o código do respectivo país.

Nessa perspectiva, foi criado o "Comitê Gestor Internet do Brasil (CG)", pela Portaria Interministerial do Ministério das Comunicações e da Ciência e Tecnologia $\mathrm{n}^{\circ}$ 147, de 31 de maio de 1995. A esse órgão compete "coordenar a atribuição de endereços IP e o registro de nomes de domínio" ". O Comitê Gestor delegou ${ }^{9}$ à Fundação de Amparo à Pesquisa do Estado de São Paulo (Fapesp) as atividades de registro de nomes de domínio, a distribuição de endereços IP e sua adequada manutenção na Internet. 
Registro de nome de domínio no Brasil

A ordem cronológica dos pedidos ${ }^{10}$ é o critério adotado para o registro de nome de domínio no Brasil. Isso quer dizer que é conferido ao primeiro requerente do registro de inscrição o direito ao nome de domínio (first come, first served). Apesar de serem recentes as recomendações do Comitê Gestor, elas já foram alteradas. É o dinamismo da Internet já influenciando suas poucas regras. De fato, atenção especial foi dada em relação ao registro de nome de domínio. Dentre as alterações, citam-se: a possibilidade de registro de nome de domínio por pessoas físicas, assim como a concessão de mais de um registro de nome de domínio por pessoa jurídica, isso porque inicialmente apenas as pessoas jurídicas poderiam ser titulares de um nome de domínio na Internet, sendo possível, para cada pessoa jurídica, apenas um registro ${ }^{11}$.

\section{É QUASE DESNECESSÁRIO DIZER}

QUE UMA DAS CONSEQÜÊNCIAS

DA INEXISTÊNCIA DE

FRONTEIRAS NA INTERNET É A

AUSÊNCIA DE UM CONTROLE

CENTRALIZADO OU DE UM

ÓRGÃO REGULADOR ÚNICO.

Assim, qualquer pessoa física ou jurídica pode solicitar o registro de nome de domínio no Brasil, desde que tenha um contato no território nacional ${ }^{12}$. O nome de domínio registrado na Fapesp poderá ser cancelado nas seguintes hipóteses: a) pela renúncia expressa do respectivo titular, por meio de documento hábil; b) pelo não-pagamento nos prazos estipulados da retribuição do registro e/ou sua manutenção; c) pelo não-uso regular do nome de domínio, por um período contínuo de 180 (cento e oitenta) dias; ou d) por ordem judicial ${ }^{13}$.

\section{Nome de domínio já registrado por terceiro}

$\mathrm{Na}$ hipótese de o registro do nome de domínio já ter sido feito por um terceiro, o interessado deverá entrar em contato com o titular do registro para um eventual acordo visando à liberação do nome de do- mínio. Para que isso ocorra, é necessário que o titular do nome de domínio o cancele na Fapesp. A partir do cancelamento, o nome de domínio fica liberado para um novo registro. Caso não haja acordo entre as partes, somente com a intervenção do poder judiciário, a questão poderá ser resolvida ${ }^{14}$.

\section{Registro de marca}

Embora Carvalho de Mendonça (1963) não defina marca especificamente, ele escreve em sua obra clássica que "a marca de comércio não é, propriamente falando, marca distintiva da mercadoria quanto à origem; é uma marca representativa da atividade mediadora do comerciante e, como a de indústria ou de comércio, também reveladora do trabalho, da capacidade e da probidade de seu titular". Ainda, uma marca pode ser definida como "todo nome ou sinal hábil para ser aposto a uma mercadoria ou produto ou a indicar determinada prestação de serviços e estabelecer entre o consumidor ou usuário e a mercadoria, produto ou serviço uma identificação" (Silveira, 1996). Além disso, marca pode ser "qualquer sinal, marca, símbolo, palavra, ou palavras que indiquem a origem ou a propriedade de um artigo para distingui-lo de suas qualidades, e do qual outros não tenham o mesmo direito de emprego para o mesmo propósito" 15 . Também se pode definir marca, de forma mais simples, como sendo "o sinal pelo qual o produto é conhecido e distinguido no mercado consumidor" (Soares, 1962).

Dada a ratificação da Ata Final da Rodada Uruguai pelo Brasil, não era possível ignorar a existência do Acordo sobre Aspectos dos Direitos de Propriedade Intelectual Relacionados ao Comércio (TRIPS ${ }^{16}$ ). O Acordo TRIPS ${ }^{17}$ define marca da seguinte maneira: "qualquer sinal, ou combinação de sinais, capaz de distinguir bens e serviços de um empreendimento daqueles de outro empreendimento poderá constituir uma marca. Esses sinais, em particular palavras, inclusive nomes próprios, letras, numerais, elementos figurativos e combinação de cores, bem como qualquer combinação desses sinais, serão registráveis como marcas. Quando os sinais não forem intrinsecamente capazes de distinguir os bens e serviços pertinentes, os Membros poderão condicionar a possibilidade do registro ao caráter distintivo que tenham adquirido pelo seu uso. Os Membros poderão exigir, como condição para o registro, que os sinais sejam visualmente perceptíveis." ${ }^{18}$ Com a entrada em vigor do acordo da OMC e, no caso, do Acordo TRIPS, foi então promulgada a Lei no 9.279 , de 14 de maio de 1996, que regula direitos e obrigações relativos à propriedade industrial. Seu art. 122 diz que "são suscetíveis de registro como marca os sinais dis- 
tintivos visualmente perceptíveis, não compreendidos nas proibições legais"19. Na verdade, a definição de marca é feita de forma negativa. Isso porque todos os sinais distintivos visualmente podem ser registrados, salvo se expressamente proibidos por lei.

O Instituto Nacional da Propriedade Industrial (INPI) tem por função executar, no âmbito nacional, as normas que regulam a propriedade industrial. Dentre essas funções, cita-se o registro de marcas. No Direito Marcário, o titular do registro de uma marca tem o poder de vedar que terceiros façam uso de sua marca registrada. Assim, o titular do registro exclui terceiros de seu campo de atuação. Ele os mantém excluídos de um campo, no qual somente ele pode movimentar-se ${ }^{20}$. A importância do registro é patente. A ordem cronológica dos pedidos é o critério adotado no Brasil para o registro de marca, assim como o é para o registro de nome de domínio na Internet.

Uma das exceções ao princípio básico do primeiro registro é o uso comercial e de boa-fé de marca ainda não registrada. "Toda pessoa que, de boa fé, na data da prioridade ou depósito, usava no país, há pelo menos 6 (seis) meses, marca idêntica ou semelhante, para distinguir ou certificar produto ou serviço idêntico, semelhante ou afim, terá direito de precedência ao registro. ${ }^{21}$ Logo, é possível a impugnação do registro de marca, se for provado o uso anterior de marca idêntica ou semelhante para produto ou serviço idêntico ou semelhante, cujo registro foi solicitado posteriormente a esse uso comprovado.

Conflito entre registros de

nomes de domínio e de marcas

Diversas atividades na Internet envolvem o uso de nomes de domínio e de marcas. Isso vem gerando uma série de conflitos, tanto do ponto de vista interno quanto internacional. Assim, citando Correa (1995), "os nomes de domínio viajam pelo mundo sem consideração de fronteiras físicas e, com freqüência, passeiam, soltos, pelos diversos segmentos de mercado, indiferentes à especificidade dos produtos ou serviços". Dada a inexistência de fronteiras na Internet, a titularidade de um nome de domínio vai além das fronteiras jurídicas de um único país. Além disso, os internautas quase sempre ligam um nome de domínio a uma marca registrada. Nesse sentido, citam-se duas decisões norte-americanas recentes. No caso "SNA, Inc. versus Array", a Corte do estado da Pensilvânia afirmou que "os usuários da Internet esperam que um site com um nome de domínio que é também uma marca registrada esteja de alguma forma relacionado com o titular da marca registrada" 22 . No mesmo sentido, a Corte do 9ํㅜㄹ Circuito, no caso "Brookfield
Comm. Inc. versus West Coast Entertainment Corp.", declarou que "usuários da Web sempre assumem, como regra de manuseio, que o nome de domínio de uma certa empresa será o nome da empresa seguido de '.com' ${ }^{23}$ ". De fato, "o desenvolvimento do comércio eletrônico fez surgir um mercado promissor de consumidores via Internet, fazendo com que o valor

\section{DIVERSAS ATIVIDADES NA INTERNET ENVOLVEM O USO DE NOMES DE DOMÍNIO E DE MARCAS. ISSO VEM GERANDO UMA SÉRIE DE CONFLITOS,} TANTO DO PONTO DE VISTA

\author{
INTERNO QUANTO \\ INTERNACIONAL.
}

da marca de uma grande empresa no ambiente internauta se tornasse algo incalculável, especialmente no campo dos nomes de domínio" (Santa Rosa, 1999). A aparição de "piratas" na Internet não tardou a acontecer. Seu principal alvo é o registro de nomes de domínio das marcas de terceiros.

Os conflitos resultantes do uso de nomes de domínio e de marcas registradas estão longe de serem solucionados definitivamente. Por essa razão, tornaram-se mais e mais freqüentes os casos de empresas que tiveram que "comprar" suas marcas na Internet, utilizadas por terceiros como de nomes de domínio ${ }^{24}$.

\section{Direito internacional privado na Intermet}

Duas teorias se opõem, frontalmente, na determinação da lei aplicável a um conflito na Internet, até mesmo nos casos de nome de domínio e de violação do Direito Marcário. A primeira delas é a chamada teoria da recepção. Nessa concepção, deve-se aplicar a lei do local onde foi cometida a infração. Dessa forma, um ato poderá ser considerado lícito ou ilícito dependendo de cada sistema jurídico. Já a segunda teoria considera que a lei aplicável ao conflito é a da emissão. Assim, a licitude ou ilicitude do ato via Internet deve ser apreciada de acordo com a lei do prestador do serviço. Ambas as teorias são, 
ao mesmo tempo, objeto de críticas e de aplausos. $O$ fato é que a jurisprudência internacional tem aplicado ambas as teorias, conforme o caso concreto. Isso porque o elemento "novo" da Internet não se encaixa adequadamente aos esquemas clássicos e rígidos do Direito.

PARA TENTAR EVITAR QUE

"PIRATAS" REGISTREM MARCAS

REGISTRADAS COMO NOMES DE

DOMÍNIO, A TITULARIDADE DO

NOME DE DOMÍNIO ESTÁ

CONDICIONADA AO FATO DE

UM TERCEIRO PROVAR A

ANTERIORIDADE DO REGISTRO

DA MARCA PERANTE O INPI.

Em função disso, foi adotada a Diretriz Uniforme para Resolução de Disputas ${ }^{25}$ pela Internet Corporation for Assigned Names and Numbers (ICANN). Também é fato que tal diretriz se baseia nas recomendações da Organização Mundial da Propriedade Intelectual (OMPI). Entretanto, um longo caminho ainda deverá ser percorrido antes que as decisões assim proferidas sejam efetivamente reconhecidas e acatadas pelos órgãos responsáveis pela prestação dos serviços de Internet nos respectivos países, assim como pelo correspondente sistema judiciário ${ }^{26}$.

\section{Direito Marcário na Internet}

Diante disso, não resta outra alternativa a não ser fazer a aplicação das regras existentes em determinado sistema jurídico. O registro de uma marca perante o INPI, no caso específico do Brasil, não gera direitos diretos que impeçam um terceiro de utilizar uma marca registrada por outro como nome de domínio na Internet. Daí decorre o conflito entre os nomes de domínio usados para identificar os sites na rede de telecomunicações sob a designação ".br" e as marcas já existentes e devidamente registradas no INPI. Isso porque a titularidade de uma marca registrada não garante integralmente a titularidade de um nome de domínio. Além disso, uma marca idêntica ou semelhante a uma outra pode ser objeto de registro no INPI se for utilizada para produtos ou serviços distintos desta. Logo, se a marca registrada no INPI for para uma determinada categoria e o nome de domínio for para um DPN distinto da categoria do registro da marca, indaga-se se o Direito Marcário poderá ou não, por analogia, dar alguma proteção ao titular da marca registrada.

Uma outra questão pode ser ressaltada. Se uma marca não registrada no INPI for utilizada comercialmente e de boa-fé por mais de seis meses, poderá o seu titular solicitar a impugnação do registro de um terceiro de nome de domínio semelhante ou idêntico a essa marca? Até que ponto o Direito Marcário, por analogia, poderá ser utilizado para responder a essas indagações? Outras hipóteses ainda poderiam ser levantadas sem que pudesse vir a ser adotada uma posição definitiva.

Diante dessas premissas e em virtude da série de conflitos que passaram a existir, algumas regras básicas foram estabelecidas. Assim, a política adotada hoje ${ }^{27}$ é a de permitir o registro de nomes de domínio, desde que não haja infração patente ao registro de marcas assegurado pelo Direito Marcário. É nesse sentido que dispõe o artigo $2^{\circ}$, letra "b" do Anexo I da Resolução n⿳0 001/98 do Comitê Gestor, ao determinar que são considerados nomes de domínio não registrável, "entre outros, palavras de baixo calão, ou que pertençam a nomes reservados mantidos pelo CG e pela Fapesp com essa condição, por representarem conceitos predefinidos na rede Internet, como é o caso do nome 'Internet' em si, ou que possam induzir terceiros a erro, como no caso de nomes que representam marcas de alto renome ou notoriamente conhecidas, quando não requeridos pelo respectivo titular". Daí resulta que as marcas notórias e/ou de alto renome ${ }^{28}$ têm sua proteção garantida na Internet.

Esse conceito resulta da influência do Direito Marcário na Internet. Isso porque o art. 125 da Lei no 9.279/96 diz que "À marca registrada no Brasil considerada de alto renome será assegurada proteção especial em todos os ramos de atividade" ${ }^{29}$. Nesse mesmo sentido, dispõe o art. 126 da referida lei, em relação à marca notoriamente conhecida ${ }^{30}$.

Entretanto, a partir do momento em que uma indagação é respondida, outras surgem quase que concomitantemente. Se a questão é clara para as marcas notórias e/ou de alto renome, o mesmo não pode ser dito em relação às marcas registradas no INPI, mas que não são consideradas notórias e/ou de alto renome. Seria preciso, então, remediar essa carên- 
cia. Dessa forma, para tentar evitar que "piratas" registrem marcas registradas como nomes de domínio, a titularidade do nome de domínio está condicionada ao fato de um terceiro provar a anterioridade do registro da marca perante o INPI. Esse princípio é hoje aplicado não apenas no Brasil mas na maior parte dos países. Assim, caso uma pessoa física ou jurídica que já seja titular de uma marca registrada seja prejudicada pela utilização dessa marca como nome de domínio na Internet, ela deverá recorrer ao judiciário, com grandes chances de obter, judicialmente, a alteração do titular do nome de domínio.

Note-se, por fim, que o Comitê Gestor no Brasil $^{31}$ não se responsabiliza, de forma expressa, pelo registro indevido de nomes de domínio nem por quaisquer ações judiciais ou extrajudiciais que resultem em violação de direitos de terceiros. Nesse sentido, a Resolução no 001/98 do Comitê Gestor não apenas é clara mas também é expressa: "a escolha do nome de domínio requerido e a sua adequada utilização são da inteira responsabilidade do requerente, o qual, ao formular o requerimento do registro exime o $\mathrm{CG}$ e o executor do registro, se outro, de toda e qualquer responsabilidade por quaisquer danos decorrentes de seu uso indevido, passando a responder por quaisquer ações judiciais ou extrajudiciais que resultem de violação de direitos ou de prejuízos causados a outrem." ${ }^{32}$

\section{CONCLUSÃO}

A função básica do nome de domínio, bem como de uma marca, é identificar um produto, serviço ou atividade, distinguindo-o de seus concorrentes. Dessa forma, um nome de domínio ou uma marca não devem ser escolhidos para gerar confusão. Seria uma violação cristalina à sua função básica: a distintividade. Como já muito bem escreveu Ferreira (1962), "destinando-se a distinguir produtos industriais ou mercadorias comerciáveis, a marca deve ter sua qualidade predominante: a distintiva. Essa qualidade é essencial de seu caráter, e decorre de sua definição. Ela há de ser distinta de outra, já usada para produto ou artigo da mesma qualidade, ou já registrada, de molde a evitar engano, confusão ou erro. Há de ser inconfundível. Ademais especial". As conseqüências de uma violação a essa regra via Internet não só tardarão a aparecer como poderão ser desastrosas.

É por essa razão que, "para regular o uso da Internet, onde, em princípio, é proibido proibir, muitos documentos de cunho legal, social e político serão emitidos, com os quais a comunidade internacional terá que se defrontar, cada país de olho em seu ordenamento jurídico interno, pois quase todos aqueles documentos certamente provocarão mudanças fundamentais, sobretudo nas leis domésticas acerca das comunicações e da propriedade intelectual" (Barroso, 1996). O mosaico de leis que pode envolver a Internet implica uma concepção jurídica nova a ser delineada para acompanhar as novas regras do jogo. Até que isso aconteça, porém, continuarão a ser aplicados os conceitos e modelos tradicionais do Direito. De fato, o que não se pode admitir é que "no vento da inovação não se comande" (D'Elia, 1996).
BARROSO, L. F. Internet e o franchising: aspectos jurídicos e operacionais. Revista da ABPI, n. 21, p. 14, mar./abr. 1996.

BENSOUSSAN, A. Internet: aspects juridiques. Paris Hermes, 1996. p. 9.

BRIGAGÃO, G. A. M. Serviço de valor adicionado. Definição legal. Diferenciação do serviço de telecomunicação. Aspectos tributários. Incidência do ISS e do ICMS. In: SEMINÁRIO INTERNACIONAL DE DIREITO DE INFORMÁTICA E TELECOMUNICAÇÕES, 11., 1997, São Paulo.
CARVALHO DE MENDONÇA, J. X. Tratado de Direito Comercial Brasileiro. São Paulo : Freitas Bastos, 1963. p. 215 e seguintes. V. 5, Parte 1.

CORREA, J. A. B. L. 0 projeto de lei da propriedade industrial e o TRIPS: a fraude na apropriação de marcas não pré-registradas. Revista da $A B P I$, n. 17, p. 36 , jul./ ago. 1995

D'ELIA, C. Verso la società dell'informazione. Informatica $e$ diritto, n. 1, p. 15, 1996.
FERREIRA, W. Tratado de Direito Comercial. São Paulo Saraiva, 1962. p. 270 e seguintes. V. 6.

GRECO, M. A. Internet e Direito. São Paulo : Dialética, 2000 p. 16.

HEY, R. Aspectos jurídicos da Internet. Revista da $A B P I, \mathrm{n}$. 19, p. 40, nov./dez. 1995. 
SANTA ROSA, D. P. Novas tendências do Direito de marcas no ciberespaço: links, frames e metatags. Revista da $A B P I, \mathrm{n}$. 41, p. 18, jul./ago. 1999.
SILVEIRA, N. A propriedade intelectual e a nova lei de propriedade industrial. São Paulo : Saraiva, 1996. p. 16.
SOARES, J. C. Tinoco. Direito de marcas. São Paulo : Atlas 1962. p. 41

NOTAS

Este artigo baseia-se em pesquisa financiada pelo NPP Núcleo de Pesquisas e Publicações da FGV/EAESP intitulada "Internet: lacuna jurídica ou inferno legal".

Agradeço pela pesquisa complementar na preparação deste artigo à minha ex-aluna no curso de Graduação da FGV/ EAESP, Isabel Garcia Calich.

\section{Intercommunication Network}

2. Artigo 61 da Lei no 9.472, de 16 de julho de 1997: "Art. 61. Serviço de valor adicionado é a atividade que acrescenta, a um serviço de telecomunicações que lhe dá suporte e com 0 qual não se confunde, novas utilidades relacionadas ao acesso, armazenamento, apresentação, movimentação ou recuperação de informações. §1ำ Serviço de valor adicionado não constitui serviço de telecomunicações, classificando-se seu provedor como usuário do serviço de telecomunicações que Ihe dá suporte, com os direitos e deveres inerentes a essa condição. § 20 É assegurado aos interessados 0 uso das redes de serviços de telecomunicações para a prestação de serviços de valor adicionado, cabendo à Agência, para assegurar esse direito, regular os condicionamentos, assim como o relacionamento entre aqueles e as prestadoras de serviço de telecomunicações."

3. Artigo 60 da Lei no 9.472, de 16 de julho de 1997: 0 serviço de valor adicionado "não constitui serviço de telecomunicações, classificando-se seu provedor como usuário do serviço de telecomunicações que lhe dá suporte, com os direitos e deveres inerentes a essa condição". Ver, a esse respeito, CELLI JR., U. A nova organização dos serviços na Lei Geral de Telecomunicações. In: SEMINÁRIO INTERNACIONAL DE DIREITO DE INFORMÁTICA E TELECOMUNICAÇÕES, 11., 1997, São Paulo.

4. É nesse sentido que dispõe a Norma 004/95, que regulamenta 0 uso de meios da Rede Pública de Telecomunicações para provimento e utilização de serviço de conexão à Internet.

\section{Resolução o 190/99.}

6. C. F Campos, em Dicionário interativo de informática, http://www.dicionario.com.br, define "teia de alcance mundial" como sendo a tecnologia usada para ter acesso à rede de Internet, fazendo tal tecnologia com que a Internet se transforme numa verdadeira teia mundial de informações. Isso é possível por meio de um conjunto de ferramentas, cujo objetivo é facilitar o acesso aos vários bancos de dados para os softwares de interfaces gráficas que navegam pela rede. A base dessa tecnologia são hipertextos que combinam linguagens como "html" e "java", o que permite aos usuários buscar informações não apenas na forma de textos, como também imagens, vídeos e sons.

7. Dispõe o Anexo II da Resolução no 001/98 do Comitê Gestor que são considerados domínios de primeiro níve no Brasil:

"Artigo único (...)

$\S \quad$ 1ํㅡonstituem Domínios de Primeiro Nível (DPNs) sob o domínio .br:

\section{I - Grupo Pessoa Jurídica:}

a) .br, destinado às instituições de ensino superior e às de pesquisa, que se inscrevem diretamente sob este domínio; este DPN 'implícito' é equivalente ao '.edu' norte-americano. Exigem-se a apresentação do comprovante de inscrição no Cadastro Geral de Contribuintes do Ministério da Fazenda (CGC/MF) e a comprovação da atividade específica;

b) .com, destinado a instituições comerciais. Exige-se 0 CGC;

c) .org, destinado a organizações não-governamentais e sem fins lucrativos. Exigem-se documentações que comprovem a natureza da instituição e o CGC. Em casos especiais, a exigência do CGC para esse DPN poderá ser dispensada;

d) .g12, destinado a instituições educacionais de primeiro e segundo grau. Exige-se o CGC;

e) .net, destinado exclusivamente a provedores de meios físicos de comunicação, habilitados legalmente à prestação de serviços públicos de telecomunicações. Exigem-se a comprovação desta atividade por documento específico e o CGC;

f) .mil, destinado aos órgãos militares

g) gov, destinado ao Governo Brasileiro, isto é, aos Três Poderes da República (Executivo, Legislativo e Judiciário), ao Ministério Público Federal, aos Estados e ao Distrito Federal. Excetuados os órgãos da esfera federal, os demais deverão ser alojados sob a sigla do Estado correspondente (ex. al.gov.br, am.gov.br, etc.) Exige-se o CGC. Poderá haver dispensa do CGC, se justificada;

h) art, destinado a instituicõos dedicadas às artes, artesanatos e afins. Exige-se o CGC. Poderá haver dispensa do CGC, se justificada; i) .esp, destinado aos prestadores especiais. Exige-se $\mathrm{CGC}$

j) .ind, destinado a instituições voltadas à atividade industrial. Exige-se o CGC;

I) .inf, destinado aos fornecedores de informação. Exigese 0 CGC;

m) .psi, destinado a provedores de serviços Internet em geral. Exige-se o CGC

n) .rec, destinado a instituições voltadas às atividades de recreação e jogos, em geral. Exige-se o CGC;

0) .tmp destinado a eventos temporários, de curta duração, como feiras, seminários, etc. Há dispensa do CGC para esta categoria;

p) .etc, destinado a instituições que não se enquadrem nas categorias anteriores. Exige-se 0 CGC.

II - Grupo Profissionais Liberais, para o qual se exige a comprovacão de inscricão no Cadastro de Pessoas Físicas do Ministério da Fazenda (CPF/MF):

a) .adv, destinado a advogados;

b) .arq, destinado a arquitetos

c) .eng, destinado a engenheiros;

d) eti, destinado a especialistas em tecnologia de informação;

e) .jor, destinado a jornalistas;

f) .lel, destinado a leiloeiros;

g) .med, destinado a médicos;

h) .odo, destinado a odontólogos;

i) .psc, destinado a psicólogos;

j) .vet, destinado a veterinários

III -Grupo Pessoas Físicas, cujo registro será efetuado sob o DPN.nom, exigindo-se para tanto a comprovação de inscrição no Cadastro de Pessoas Físicas do Ministério da Fazenda (CPF/MF) do titular ou do seu responsável." 
8. Art. 1ำ da Portaria Interministerial no 147/95, de 31 de maio de 1995, do MC/MCT. "São atribuições do Comitê Gestor: I. acompanhar o provimento de serviços Internet no País; II. estabelecer recomendações relativas estratégia da implantação e interconexão de redes, análise e seleção de opções tecnológicas, e papéis funcionais de empresas, instituições de educação, pesquisa e desenvolvimento (IEPD); III. emitir parecer sobre a aplicabilidade de tarifa especial de telecomunicações nos circuitos por linha dedicada solicitados por IEPDs; IV. recomendar padrões, procedimentos técnicos e operacionais e código de ética, para todos os servicos Internet no Brasil; V. coordenar a atribuição de endereços IP (Internet Protocol) e o registro de nomes de domínio; VI. recomendar procedimentos operacionais de gerência de redes; VII. coletar, organizar e disseminar informações sobre o serviço Internet no Brasil; e VIII. deliberar sobre quaisquer questões a ele encaminhadas."

9. Resolução no 02, de 15 de abril de 1998, do Comitê Gestor.

10. Art. 1ํ da Resolução no 001/98, de 15 de abril de 1998, do Comitê Gestor. Comitê Gestor.

12. Art. 2o da Resolução no 001/98 do Comitê Gestor: "É permitido o registro de nome de domínio tão-somente para entidades que funcionem legalmente no País, profissionais liberais e pessoas físicas, conforme disposto no Anexo II desta Resolução."
11. Ver art. 1ำ do Anexo I da Resolução no 001/98 do

16. É verdade, porém, que o Brasil tinha um prazo de dez anos para implementar as disposições do Acordo TRIPS, a contar da entrada em vigor da OMC.

17. Trade Related Aspects of Intellectual Property Rights.

18. Art. 15.1 do TRIPS. Sobre o TRIPS e a OMC, ve COSTA, L. M. OMC: manual prático da Rodada Uruguai. São Paulo : Saraiva, 1996; LEONARD0S, G. S. A data de aplicação no Brasil do acordo sobre direitos de propriedade intelectual relacionados ao comércio: TRIPS Revista da $A B P I$, n. 17, p. 6-12, jul./ago. 1995; CARMINATTI, A. A aplicação do TRIPS na ordem jurídica interna. Revista da ABPI, n. 17, p. 13-17, jul./ago. 1995 BASSO, M. O Direito Internacional da propriedade intelectual. Porto Alegre : Livraria do Advogado, 2000.

19. 0 art. 124 da Lei no 9.279 , de 14 de maio de 1996 , determina 23 incisos de sinais não registráveis.

20. Ver FARIA CORREA, J. A. B. L. Eficácia dos registros de marca. Revista da ABPI, n. 23, p. 48, jul./ago. 1996.

21. Art. 129 , § 1으 da Lei no 9.279, de 14 de maio de 1996 Ver, a esse respeito, PIMENTA, L. E. Montaury. Uso anterior como fundamento para impugnação a pedido de registro de marca. Revista da $A B P I$, n. 24 , p. 31, set./ out. 1996: "apesar de o sistema atributivo continua prevalecendo, o legislador conclui pela necessidade de se abrir uma (entre outras) exceções (sic) a essa regra."

22. 199 WL 359786: "Internet users expect that a site with a domain name that is a trade mark is somehow "Extingue-se o direito de uso de um nome de domínio registrado na Internet sob o domínio .br, ensejando seu cancelamento, nos seguintes casos: I - pela renúncia expressa do respectivo titular, por meio de documentação hábil; II - pelo não pagamento nos prazos estipulados da retribuição pelo registro e/ou sua manutenção; III pelo não uso regular do nome de domínio, por um período contínuo de 180 (cento e oitenta) dias; IV - pela inobservância das regras estabelecidas nesta Resolução e seus Anexos; V - por ordem judicial."

14. Artigo 7ํㅡ, inc. V da Resolução no $001 / 98$ do Comitê Gestor.

15. Ver WRIGHT, M. Inventions, patents and trademarks. New York/London : McGraw-Hill, 1933, p. 29: "any sign, mark, symbol, word, or words which indicate the origin or ownership of an article as distinguished from its quality, and which others have not the equal right to employ for same purpose." related to the owner of the trademark."

23. 174 F3d 1036, 1045 (9 $9^{\text {th }}$ Cir. 1999): "Web users often assume, as a rule of thumb, that the domain name of particular company will be the company name followed by '.com'."

24. Por exemplo, Taco Bell, MTV, Kentuck Fried Chicken, McDonald's, Avon, Kaplan, entre outras. Cita-se, ainda, a sociedade W3 Systems Inc., que registrou mais de 300 nomes de domínio correspondentes a marcas registradas, sendo inclusive algumas delas notórias e/ ou de alto renome. São elas: La Perla, Tartine et Chocolat, Agnes B, Euro-Tunnel, Pastis 51, TF 1, Alain Manoukian, Black-Decker, Galerie Lafayette, dentre outras. Ver, a esse respeito, MONTEIRO, J. Contrefaçon et autres atteintes aux marques sur Internet. Revista da ABPI, n. 27, p. 1930, mar./abr. 1997
25. Uniform Dispute Resolution Policy (UDRP).

26. A esse respeito, ver estudo de BASSO, M. A arbitragem como método de solução de controvérsias na Internet: atualidade do sistema de nome de domínio. In: CONGRESSO DA UIBA, 14., 2000, Fortaleza. Fortaleza : OAB, 2000.

27. Essa tendência não é exclusiva do Direito brasileiro. A maior parte dos países também a adotou.

28. Ver estudos que tratam da diferenciação entre marca de alto renome e marca notoriamente conhecida, SOARES, J. C. Tinoco. Marca de alto renome e marca notoriamente conhecida. Revista da ABPI, n. 24, p. 11 17, set./out. 1996; SOARES, J. C. Tinoco. 0 tratamento das marcas de alto renome e das marcas notoriamente conhecidas na Lei 9.279/96. Revista da ABPI, n. 28 maio/jun. 1997. Apesar de não se tratar de trabalho recente, ver importante estudo de SOARES, J. C. Tinoco. Direito de marcas. 1. ed. São Paulo: Atlas, 1962. p. 107 e seguintes. Nesse trabalho, 0 autor cita 0 entendimento do Direito e da jurisprudência na França, na Inglaterra, nos Estados Unidos, na Alemanha e no Brasil a respeito de marcas notórias. No Brasil, segundo o autor, são consideradas como notórias as marcas - sendo muitas delas ainda atuais e outras já nem tanto - como Chiclets, para goma de mascar; Crush, para refrigerantes; Cinzano, para bebidas alcóolicas; Keds, para botas e sapatos de borracha; Pyrex, para vidros e artefatos de vidro; AlkaSeltzer, para produtos farmacêuticos; Lambretta, para veículos; Zippo, para isqueiros, entre outras.

29. Art. 125 da Lei o 9.279 , de 14 de maio de 1996 .

30. Art. 126 da Lei no 9.279 , de 14 de maio de 1996 "Art. 126. A marca notoriamente conhecida em seu ramo de atividade nos termos do art. 6o-bis (I) da Convenção da União de Paris para Proteção da Propriedade Industria goza de proteção especial, independentemente de estar previamente depositada ou registrada no Brasil. § 1ㅇ A proteção de que trata este artigo aplica-se também às marcas de serviço. § 20 INPI poderá indeferir de ofício pedido de registro de marca que reproduza ou imite, no todo ou em parte, marca notoriamente conhecida."

31. Essa decisão não é exclusiva do Comitê Gestor brasileiro. Os outros órgãos equiparados nos demais países também tomaram essa mesma atitude.

32. Art. 1ํㅗ § 3ำ da Resolução ํㅜ 001/98 do Comitê Gestor. 